Bates College

SCARAB

8-30-2017

\title{
Midwestern US Farmers Perceive Crop Advisers as Conduits of Information on Agricultural Conservation Practices
}

Francis R. Eanes

Bates College, feanes@bates.edu

Ajay S. Singh

Brian R. Bulla

Pranay Ranjan

Linda S. Prokopy

See next page for additional authors

Follow this and additional works at: https://scarab.bates.edu/faculty_publications

\section{Recommended Citation}

Eanes, F.R., A.S. Singh, B.R. Bulla, P. Ranjan, L.S. Prokopy, M. Fales, B. Wickerham, and P.J. Doran. (2017). Midwestern US Farmers Perceive Crop Advisers as Conduits of Information on Agricultural Conservation Practices. Environmental Management. 60(5), 974-988; doi: 10.1007/s00267-017-0927-z 
Authors

Francis R. Eanes, Ajay S. Singh, Brian R. Bulla, Pranay Ranjan, Linda S. Prokopy, Mary Fales, and Benjamin Wickerham 


\title{
Farmers perceive crop advisers as conduits of information on agricultural conservation practices
}

Francis R. Eanes ${ }^{1,4}$, Ajay S. Singh ${ }^{2,4}$, Brian R. Bulla ${ }^{3}$, Pranay Ranjan ${ }^{4}$, Linda S. Prokopy ${ }^{4}$, Mary Fales $^{5}$, Benjamin Wickerham ${ }^{5}$ and Patrick J. Doran ${ }^{5}$

${ }^{1}$ Program in Environmental Studies, Bates College

${ }^{2}$ Department of Environmental Studies, California State University at Sacramento

${ }^{3}$ Department of Government and Justice Studies, Appalachian State University

${ }^{4}$ Department of Forestry and Natural Resources, Purdue University

${ }^{5}$ The Nature Conservancy (Michigan)

Acknowledgments:

This work was funded by The Nature Conservancy (contract number 101915-1) through support from the Cook Family Foundation (P102900, Activity 105811) and Mott Foundation (P116413).

\begin{abstract}
:
Nonpoint source (NPS) pollution from agricultural land uses continues to pose one of the most significant threats to water quality in the U.S., with measurable impacts across local, regional, and national scales. The impact and influence of targeted conservation efforts are directly related to the degree to which farmers are familiar with and trust the entities providing the information and/or outreach. Recent research suggests that farmers consistently rank independent and retailaffiliated crop advisors (CAs) as among the most trusted and influential sources for agronomic information, but little is understood about whether farmers are willing to receive advice from CAs on the use of practices which conserve soil and water, and if so, whether CAs will be perceived as influential. We present survey $(n=1,540)$ and interview $(n=34)$ data from farmers and CAs in Michigan's Saginaw Bay (Lake Huron) watershed to explore these questions. Results suggest that farmers do not expect CAs to integrate conservation advice into the services they currently provide, but are generally open to such a change and would find their advice to be credible and influential. We discuss these results, along with perceived barriers and opportunities to CAs partnering with traditional conservation agencies to enhance the impact of voluntary conservation programs.
\end{abstract}

\section{Recommended Citation:}

Eanes, F.R., A.S. Singh, B.R. Bulla, P. Ranjan, L.S. Prokopy, M. Fales, B. Wickerham, and P.J. Doran. (2017). Midwestern US Farmers Perceive Crop Advisers as Conduits of Information on Agricultural Conservation Practices. Environmental Management. 60(5), 974-988; doi: 10.1007/s00267-017-0927-z 


\subsection{INTRODUTION}

Nonpoint source (NPS) pollution from agricultural land uses continues to pose one of the most significant threats to water quality in the U.S., with measurable impacts across local, regional, and national scales (Allan et al. 2013; Rissman and Carpenter 2015; Kerr et al. 2016a). Coordinated attempts by governmental and nongovernmental entities to improve water quality are increasingly relying on outreach efforts and incentive programs designed to influence farmers' voluntary adoption of soil and water conservation practices (Potoski and Prakash 2002). The threat of top-down regulation resulting from nonpoint source pollution litigation (e.g. Des Moines Water Works suing several upriver drainage districts for exporting excess nitrates) has intensified some efforts to increase the efficacy and impact of voluntary conservation (Eller 2015; Eller 2016). While there are many factors which facilitate the adoption of conservation practices (see Prokopy et al. 2008), one factor for the influence of conservation outreach is context and messenger specific (Knowler and Bradshaw 2007). Moreover, the impact and influence of targeted conservation outreach efforts (e.g., Fales et al. 2016) are directly related to the degree to which farmers are familiar with and trust the entities providing the information and/or outreach (Mase et al. 2015). Recent research suggests that farmers consistently rank independent and retail-affiliated crop advisers (CAs) as among the most trusted and influential sources for agronomic information (Prokopy et al. 2015; Singh et al. in review). But while CAs are seen as influential on decisions related to crop production, there is little evidence of their influence on decisions related to implementing soil and water conservation practices on cropland.

Understanding this chain of influence - i.e. from initial knowledge of a practice to its implementation - in the context of soil and water conservation practices is challenged by the 
multifunctionality of agroecosystems and their associated actors (Harden et al. 2013). Since the provisioning of public goods (e.g., water quality) may conflict with the economic incentives to provide private goods (e.g., agricultural products), governments enter into a principal-agent relationship with farmers to ensure the delivery of public goods (Stoneham et al. 2003). Principal-agent theory explains the complex intra- and inter-organizational relationships whereby a principal (e.g., government) contracts with an agent (e.g., farmers) to accomplish tasks and goals that the principal is otherwise unable to undertake (e.g., wildlife conservation on private lands) (Mitnick 1980). Principals contractually delegate the provisioning of a good or service to agents through a variety of financial compensation mechanisms that motivate behavior and ultimately lead to goal attainment (Latacz-Lohmann and Van der Hamsvoort 1997). For example, an employer provides an employee pay and benefits for work rendered. Problems related to information asymmetry - i.e. when one actor has information that the other does not between the principal and agent, however, can pose significant challenges to the relationship and result in slippage - that is, a measurable difference between principles' expectations and agents' actions (Cousins 2006). Information asymmetry creates what is known as a principal-agent dilemma. To overcome the principal-agent dilemma, principals conduct monitoring and, when needed, sanctioning of agent performance (Mitnick 1980; Braun and Guston 2003; Coleman 1990). Principals can perform monitoring and sanctioning of agents either directly or indirectly through third-party intermediaries (McCubbins and Schwartz 1984). However, the functionality of the principal-agent relationship can be complicated when matters of authority, difficulty in measuring and monitoring agent performance, and incentive transparency are not clearly delineated, and when multiple information intermediaries are present (Floress et al. 2011). 
Nonpoint source pollution in agricultural landscapes presents a potentially complex situation for the principal-agent dilemma. While the government (writ large) is typically construed as the principal and individual farmers as agents, this role conceptualization belies the complexity of the relationship. Multiple entities can reasonably be construed as principals who have an interest in outcomes associated with on-farm conservation practices, including the federal government, state governments, non-profit entities (e.g. environmental conservation groups, commodity groups, agribusiness associations), and for-profit entities (e.g. agribusinesses). While these principals may share the broad goal of fostering conservation, such as water quality, their jurisdictional authority, statutory limitations, primary motivations, and means of contracting with farmers do not always overlap, and may in fact work at crosspurposes. Moreover, many of these principals typically do not contract directly with farmers, but instead execute their goals through intermediaries who provide critical technical support, information, and/or cost-share related to conservation practices (Lemos et al. 2012; Carr and Wilkinson 2005). Intermediaries include both public entities - e.g. the Farm Services Agency (FSA), Natural Resources Conservation Service (NRCS), Soil and Water Conservation Districts (SWCDs), and University Extension - as well as private entities - e.g. environmental nongovernmental organizations (NGOs) and hunting/fishing groups - whose missions align with the government's legislative and administrative policies directed at the provisioning of public goods.

We argue that CAs may be uniquely positioned to addressing the principle-agent dilemma by helping to align the government's goals of providing public goods with the goal of farmers to provide private goods. Given farmers' high level of trust in CAs and influence that CAs have on farm management decisions, CAs may be effective intermediaries in helping 
farmers make informed on-farm natural resource conservation decisions that improve off-farm water quality. But despite their growing importance to farmers' decision making, no published literature has explored the use of CAs delivering information specific to conservation practices. In this article, we examine farmers' perceptions of CAs as a potential delivery mechanism for conservation entrepreneurs. We use survey and interview data from farmers in the central Great Lakes region to better understand the barriers and opportunities that may be associated with CAs assuming this role. In particular, we evaluate: (1) the relative level of trust that farmers have in CAs as sources of conservation information; (2) the degree to which CAs influence farmers' conservation practices; and (3) farmers' attitudes with respect to CAs as potential conservation partners. While there are certified CAs associated with a number of organizations and government agencies (e.g. agribusiness, Extension, NRCS), we define a CA as anyone who provides agricultural information and services to farmers either through fee-for-service or incentive-based payments. Below we highlight existing research on the relationship between CAs and farmers in order to more thoroughly illuminate the contribution we hope to make with this article.

\subsection{LITERATURE REVIEW}

\subsection{The Role of Crop Advisers}

The emergence of contemporary CAs since the 1990s is largely due to a coordinated effort among vested parties - including the Department of Agriculture, Environmental Protection Agency, American Society of Agronomy (ASA), and the fertilizer and pesticide industries - to raise industry standards, mollify potential questions regarding conflicts of interest between 
industry and farmers, and to create a market for providing agricultural advice/expertise and services (Wolf 1995). In addition to the ASA-run Certified Crop Adviser program that initially emerged from these efforts, the National Association of Independent Crop Consultants and the Certified Professional Crop Consultant-Independent both run programs for crop advisors who do not have any direct involvement with product sales to farmers (Wolf 1995). This positions independent CAs as a natural intermediary not only between farmers and agricultural industries in production of private goods, but to provide advice and services to farmers that couple the goals of the farmer with goals of government in the provision of public goods.

Given their fairly new role in agriculture, literature on CA-farmer relationships is relatively sparse compared to other social components of agricultural systems. Shah et al. (2015) surveyed nearly 200 certified CAs and 200 farmers in four mid-western U.S. states - Iowa, Illinois, Ohio, and Wisconsin and found that, on average, individual CAs work with 91 farmers through in-person meetings and their average farmer-client operates 590 acres. A study of Illinois farmers found that as farm size increased, farmers were more likely to use CAs; over $40 \%$ of farmers operating farms larger than 1,000 acres in size use CAs, while only $25 \%$ of farmers working on less than 500 acres use CAs (Norvell and Lattz 1999).

Among the many sources of information on agronomic practices, CAs are among the most trusted by farmers for advice and information for their farm management decisions (Prokopy et al. 2015; Singh et al. in review). Agricultural consultants, which include both certified CAs as well as fertilizer, equipment, and/or seed representatives, were the second-most reliable sources for guidance on water-use-efficiency practices in the water-limited High Plains region (Kromm and White 1991). Similarly, Michigan corn growers said that CAs were the most-preferred sources of information for nitrogen application decisions intended to increase 
yields (Stuart et al. 2014). In a survey of Midwestern corn producers, certified CAs trailed only farm chemical dealers, seed dealers, and family members as the most influential entities for making decisions about agricultural practices and strategies - an effect that becomes even more pronounced on larger farms (Prokopy et al. 2015)., However, farmers typically report that they trust Extension, NRCS, and SWCDs the most (Mase et al. 2015; Singh et al. in review) regarding information on conservation practices that affect soil and water quality. The trust in these individuals and institutions has been explained in part by the longevity of these institutions, their relative familiarity and visibility within the agricultural community, and the fact that natural resource conservation is directly within their purview (Rosenberg and Margerum 2008; Davenport et al. 2007). Questions remain, however, regarding whether farmers' trust in CAs for general agronomic advice will translate into greater trust in, and influence of, CAs as sources of conservation information.

CAs play an important role in facilitating the transfer of information pertaining to management decisions and innovative production practices. Prokopy et al. (2012), for example, suggest that CAs serve as a potential conduit of advice of climate information to help farmers adjust operational decisions to seasonal forecasts. Likewise, Gal et al. (2011) assert that farmers are not routinely in a financial position to test, experiment, or adopt unproven practices so they turn to CAs to provide additional analysis and evaluation of potential costs and benefits of new innovations prior to their implementation. Similarly, Lemos et al. (2014) found that CAs can serve as conduits of climate-related conservation information to farmers, but most likely only when working in supportive organizations and when that information does not interfere with the advisers' primary agronomic purpose. Perhaps most importantly, Singh et al. (in review) found that the degree to which farmers trust CAs and other information sources has a large and 
significant effect on the likelihood that those sources influence farmers' decision making, and that influence may vary depending on the type and time horizon (i.e. short- medium-, and longterm) of the decision in question.

Others, though, have found that farmers may also discount certain CA advice in specific situations. Sheriff (2005), for example, found that farmers disregard the recommendations of their adviser when both parties fundamentally disagreed over the best planning and projection model for the farm and expected crop yields. Furthermore, when fertilizer input costs were low, an over-application of nitrogen was seen by farmers as an economically rational decision and as quasi crop insurance, despite CAs' recommendations to the contrary (Sheriff 2005; Osmond 2015; Davidson et al. 2014). Clearly, some of CAs' agronomic advice is being disregarded by farmers, especially in the context of fertilizer application.

\subsection{CAs as Potential Conservation Entrepreneurs}

As the need for agricultural conservation increases, research has suggested that CAs occupy an advantageous niche within broader agricultural-information milieu, and may be uniquely positioned to act as critical conservation entrepreneurs by incorporating conservation advice into the services they currently provide to farmers. For the purposes of this research, we define a conservation entrepreneur as someone who acts as a sort of clearinghouse, matching conservation problems with conservation information and solutions. For example, Cerf et al. (2011: 17) have suggested that CAs may be able to transcend traditional characterizations as detached experts who merely deliver technical information or facilitate procedural best practices, and instead become change agents who embrace new opportunities that might "enable farmers to develop a new understanding of their unit of action (the ecosystem versus the agrosystem)." Similarly, CAs may play a central role in disseminating to their farmer-clients information that 
has been passed along to CAs by the traditional university-ag extension services and related personnel (Davidson et al. 2014). CAs can help facilitate the transition from an input-intensive agricultural logic to a conservation-logic by providing new and different sources of information, by offering expanded measures of agronomic success such as the Wisconsin Soil Health Scorecard (Roming et al. 1996), and by collaborating with new partners who can help chart new directions in sustainable agriculture that will improve water quality (Chantre and Cardona 2014). As conservation entrepreneurs, CAs may be able to be an intermediary between governments and farmers by matching the goals and objectives of a farmer with programmatic opportunities provided by government and other institutions.

However, despite the aspirational appeal of CAs becoming conservation entrepreneurs, these theoretical suggestions remain speculative and empirically underexplored. This article begins to address these issues by empirically examining principal-agent relationships in the context of agricultural conservation. This research is grounded in a conceptual model that describes the complex network of multiple actors involved in the current conservation landscape. Figure 1 depicts that network in which society, via representatives, provides governments and their agencies the authority and resources necessary to attain the goal of furnishing adequate water quality. Government agencies, such as the EPA and NRCS, then enter into contractual relationships with agents, such as farmers and landowners, via policies and programs designed to incentivize actions or behaviors that ensure the provision of water quality. Farmers also provide private goods, such as food and fiber, in exchange for monetary compensation. We argue that CAs, who already provide agricultural advice to farmers in exchange for compensation, could additionally become brokers of information between farmers and government agencies for the purposes of overcoming the dilemma of information asymmetry in the context of conservation. 
However, just as there are principal agent dilemmas with other contractual relationships, we hypothesize that there will be problems associated with this relationship. To understand some of these problems and opportunities associated with CAs becoming conservation entrepreneurs, we explore farmers' perceptions of a system in which CAs incorporate conservation information and recommendations into the services they currently provide.

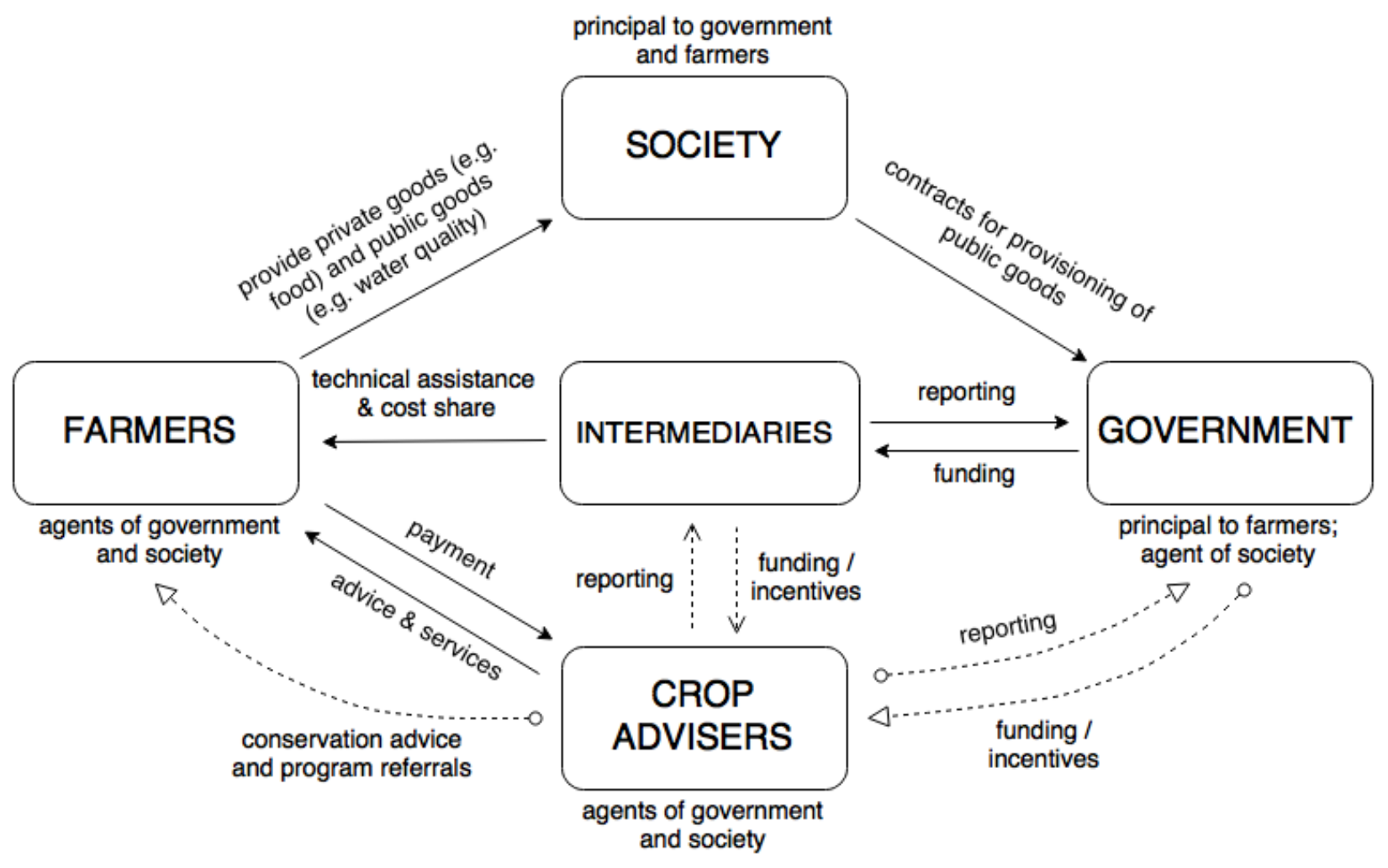

Fig. 1 Conceptual diagram of the principal-agent relationships currently involved in agriculture and water quality. Solid-line arrows represent relationships and functions that currently exist, while dotted-line arrows represent the potential future role of CAs as conservation entrepreneurs

\subsection{METHODS}

\subsection{Study Area \& Background}

The Saginaw Bay watershed, part of the Lake Huron basin, covers more than $22,500 \mathrm{~km}^{2}$ and all or part of parts of 22 counties in the heart of Michigan's agricultural belt (Figure 2). More 


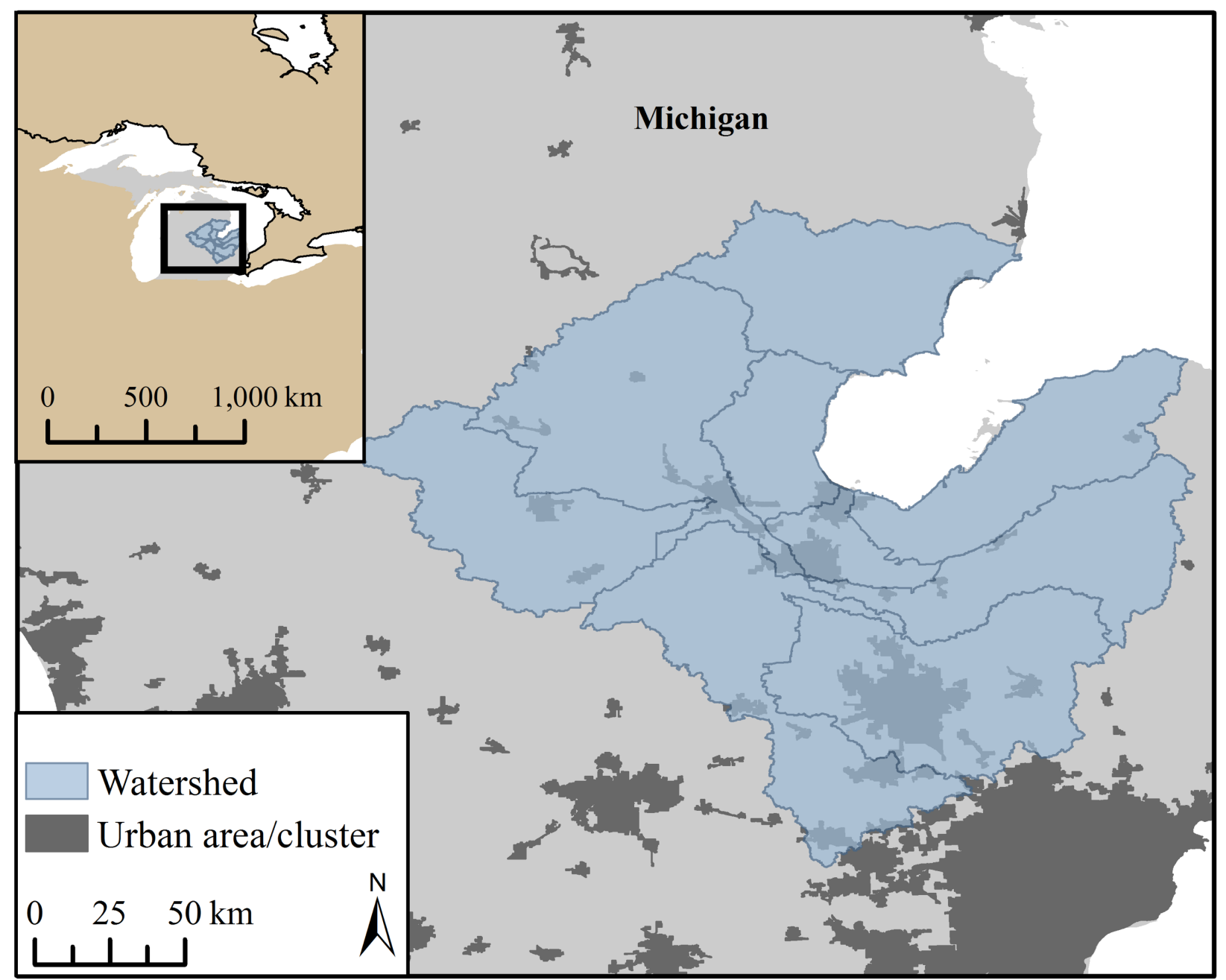

Fig. 2 Map of Saginaw Bay watershed

than 11,000 km of streams and rivers, as well as the US's largest stretch of freshwater coastal wetlands, support 90 species of fish, 138 endangered or threatened species, and drinking water for the watershed's 1.4 million residents (Saginaw Bay Watershed Initiative Network 2016). Despite these rich amenities, which support recreation and tourism, $45 \%$ of the watershed's land use is agricultural. Due to pollution impacts from industry and agriculture, the Saginaw Bay is federally listed as an Area of Concern (US EPA 2012). Nonpoint source pollution persists as a significant challenge in the watershed (Kerr et al. 2016a; Sowa et al. 2016), and has become the 
focus of many conservation programs aimed at reducing the impacts of NPS (Fales et al. 2016;

Kerr et al. 2016b), including the Saginaw Bay Regional Conservation Partnership Program (RCPP). Funded through USDA, the RCPP provides cost-share monies to qualifying farmers to adopt specific conservation practices - i.e. cover crops, reduced tillage, and nutrient management plans - with the intent of improving regional surface water quality (USDA-NRCS 2016). This study was commissioned as part of a larger effort to evaluate the Saginaw Bay RCPP effort in which CAs were encouraged to recruit farmers to participate.

\subsection{Survey}

To evaluate farmers' perceptions of crop advisers in the Saginaw Bay watershed, we employed a mixed methods approach that combined a mail and web-based survey with in-person interviews with farmers. In February 2016, surveys were distributed following a 5-wave method (Dillman 2014). The population of interest consisted of agricultural landowners in the Saginaw Bay watershed. A sampling frame was generated through a Freedom of Information (FOIA) request for contact information of individuals, businesses, and organizations in the state of Michigan that have received Farm Bill funding in years 2014. The request generated 24,619 names and addresses of agricultural landowners in the state of Michigan. The addresses of landowners were geocoded to assess whether addresses resided within the Saginaw Bay watershed. Contacts who resided outside the watershed were removed, reducing the number of landowners to 5,275 addresses. After removing duplicate names and addresses from the list, the number of contacts was reduced to 4,242 landowners. We randomly selected a sample of 3,000 landowners as participants for the final sample. 


\subsection{Interviews}

In addition to the survey, 22 semi-structured, in-person interviews were conducted with farmers to elicit additional information about their perceptions of water quality conditions and conservation practices. A stratified random sample of 100 survey respondents were contacted to participate in an in-person interview. Stratification was conducted to ensure maximum diversity across four characteristics, including farm size, crops grown, and farmer age and gender. Interviews were conducted on-farm between June 21 and August 8, 2016. Interviews were transcribed and qualitatively analyzed, using NVivo Pro version 11, for key themes and categories of interest, including perceived barriers to and benefits of using a CA, reasons for trusting (or not) CA advice, and perceptions of CAs offering conservation recommendations. An intercoder reliability test, conducted to ensure consistency of data analysis, resulted in a kappa of 0.88 , indicating strong intercoder consistency.

\subsection{RESULTS}

A total of 1,461 surveys were completed for a response rate of $49.7 \%$. Of these, $892(61 \%)$ identified themselves as farmers, with $91.3 \%$ of farmers identifying as male, and $8.7 \%$ as female, with a mean age of 61.3 years old (ranging from 27 to 96). On average, farmers have completed at least some college (i.e. more than a high school diploma, but less than a 2- or 4-year degree), with $19.0 \%$ of having completed a 4 -year college or postgraduate degree. The mean and median farm size among farmer respondents was 582 acres (236 ha) and 240 acres (97 ha), respectively.

Approximately three in five (59.3\%) farmers in the Saginaw Bay watershed currently use a CA, 33.7\% do not use and have never used a CA, and the remaining $7.0 \%$ currently do not use 
a CA but have used one in the past. Among those who currently use a CA, $24.5 \%$ use an independent CA, while the rest work with one or more retail-affiliated CAs. Use of a CA shows is, positive association with the size of a producer's farm, a negative association with a farmer's age, and is unassociated with their level of education. Based on the disproportionate acreage farmed by respondents who currently use a CA compared to those who do not, we estimate that approximately $85 \%$ of the Saginaw Bay watershed's cropland is influenced (to some degree) by a CA.

In follow-up interviews, farmers identified several benefits of using CAs. These include the perceptions that CAs are timely and responsive, provide cutting edge information, and especially in the case of independent CAs - offer unbiased advice. Like other sources of information, farmers said that the most credible and beneficial CAs were those that were not too pushy, and were familiar with the unique agronomic dynamics of their farm and region. One farmer, for example, said "We have a guy that works with us all the time. He comes back, he makes recommendations off [of] soil tests. And then if we have any problems anytime ..., he comes back and he does tissue tests and stuff like that. So they're very, very important. We worked with some other people, tried some other people. Soil test people, they got ideas of how they want to do things. And we think these guys are as good as you can get because they work here and they work in the Thumb [geographic] area a lot where it's the same kind of crops that we do - the sugar beets, the dry beans, stuff like that."

Other farmers identified CAs' nimbleness, flexibility, and relative lack of institutional bureaucracy as additional advantages. Several mentioned that they have developed enough trust with their CA to completely delegate certain farm tasks, even without prior consultation. One farmer noted that "If there's some new product or something different, [my CA] will meet with 
me. But if [my fields] needs lime, [he] just puts it on. We have a set program. When you soil sample about 3,000 acres a year, don't come meet with me and ask about lime. Just put it on. We can talk about phosphorus and potassium on a rainy day, because those are a lot more money, and maybe we're going to get manure there next year. So we let it go. But it's like, 'Hey, it needs lime.' Order the trucks. Get it there. Send me a text so I don't chisel plow the whole field or leave you a spot to dump it. Perfect. Just get it done."

Farmers cited their relatively small farm size and the related cost of hiring a CA as reasons for not currently using a CA. Others indicated that they (the farmer) know their fields better than anyone else, and feel confident that the methods and practices that have brought them success in the past will persist into the future, obviating the need for an outside consultant to "tell them what to do," as some farmers put it.

\subsection{Trust in CAs}

When surveyed about the extent to which they trust different sources of information about conservation practices, farmers rated independent CAs and retail CAs as the fifth and seventh most trustworthy, respectively, out of seventeen total information sources. When responses from farmers who do not currently use a CA were excluded, however, independent and retail CAs were the third- and fifth-most trusted entities, respectively, and were rated on average as moderately trusted sources of conservation information (Figure 3). Trust in independent CAs ranks third after producers' mean level of trust in the FSA and Michigan State University Extension, while trust in retail CAs follows all of those in addition to SWCDs and the NRCS. Compared to farmers who currently use a CA, non-CA farmers are significantly less trusting of independent CAs (two-sample $\mathrm{t}[649]=9.90, \mathrm{p}=0.001$ ), retail-affiliated CAs (two-sample $\mathrm{t}[671]=9.80, \mathrm{p}=0.001)$, fertilizer representatives (two-sample $\mathrm{t}[717]=6.54, \mathrm{p}=0.001)$, commodity 
groups (two-sample $\mathrm{t}[672]=5.27, \mathrm{p}=0.001$ ), Michigan Agribusiness Association (two-sample $\mathrm{t}[571]=5.56, \mathrm{p}=0.001)$, Michigan Farm Bureau (two-sample t $[728]=3.50, \mathrm{p}=0.001$ ), and NRCS (two-sample $\mathrm{t}[688]=2.41, \mathrm{p}=0.02$ ). Non-CA farmers, however, are significantly more trusting of sportsmen groups (two-sample $\mathrm{t}[689]=4.96, \mathrm{p}=0.001$ ), environmental groups (two-sample $\mathrm{t}[625]=5.34, \mathrm{p}=0.001$ ), and The Nature Conservancy (two-sample $\mathrm{t}[522]=3.35, \mathrm{p}=0.001$ ).

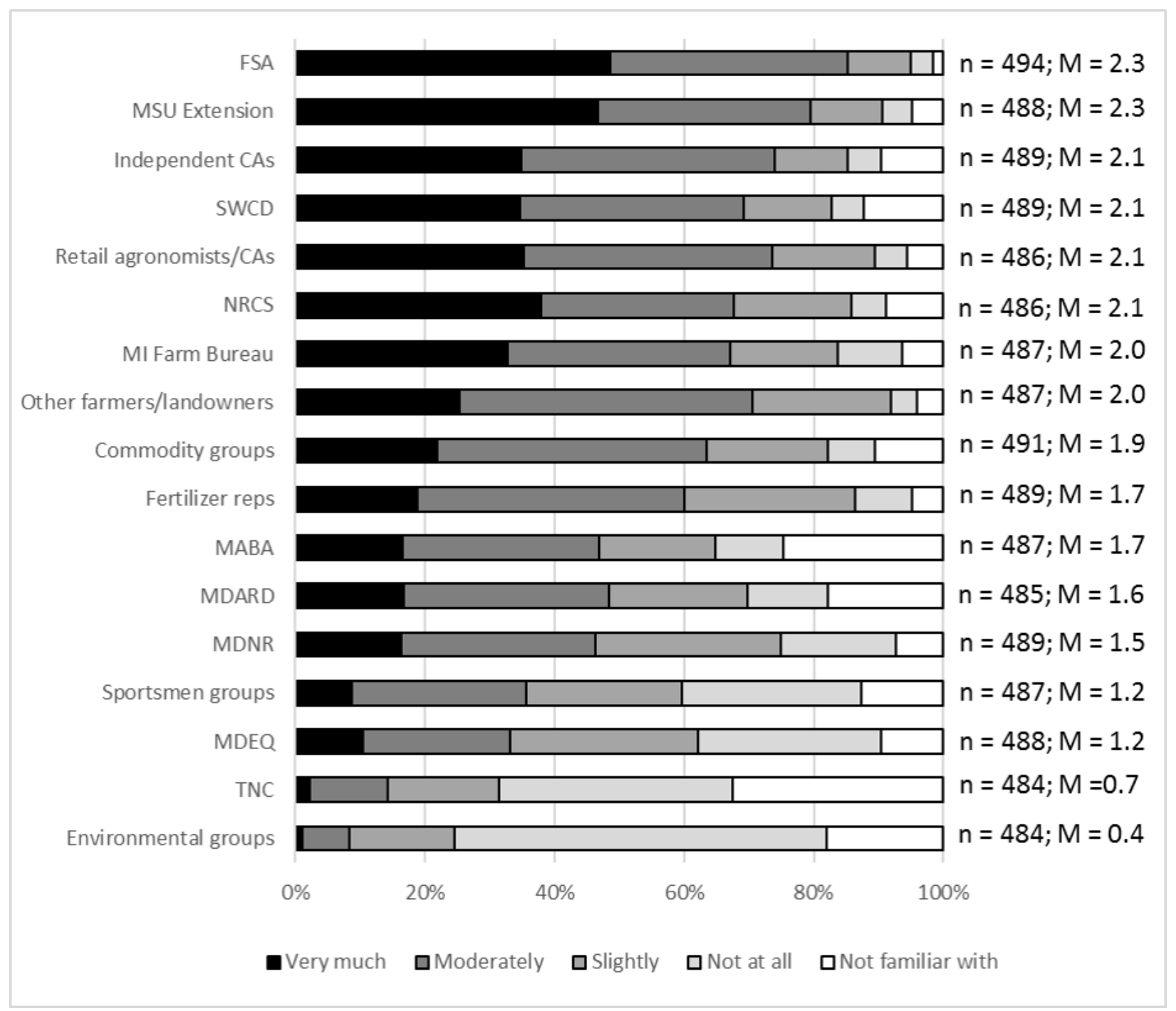

Fig. 3 Levels of trust in different sources for information about conservation among respondents who currently use a CA. Mean (M) trust was measured on a scale of 0 (not at all) to 3 (very much). MDARD refers to MI Dept. of Ag. \& Rural Development. MDNR refers to MI Dept. of 
Natural Resources. MDEQ refers to MI Dept. of Enviro. Quality. MABA refers to MI

Agribusiness Assn. TNC refers to The Nature Conservancy.

\subsection{Influence of CAs}

CAs provide a variety of services and information for producers, which vary in part based on their capabilities and expertise and the characteristics of any given farm operation. These services and information can have an influence on farm management decisions (Figure 4).

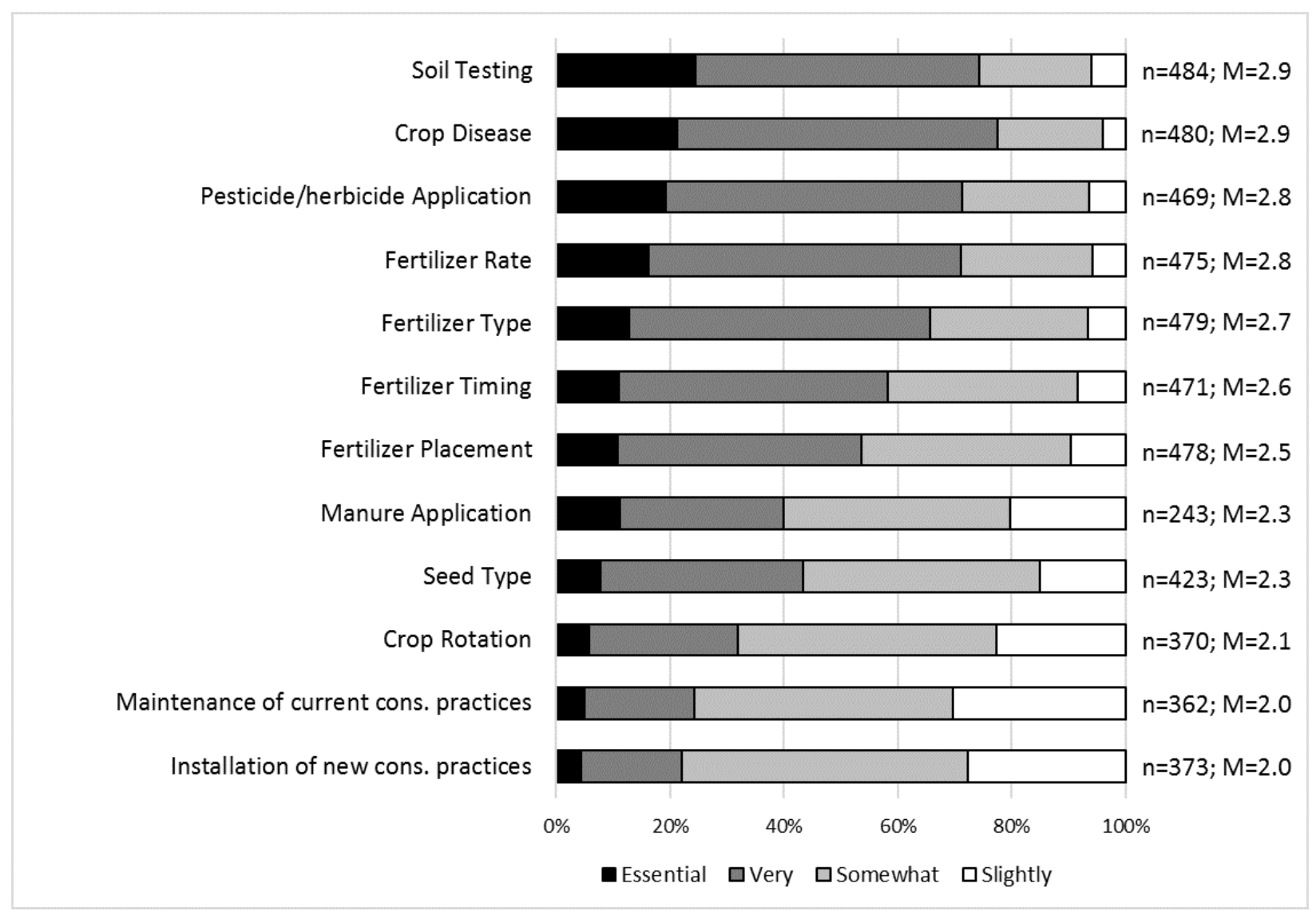

Fig. 4 Percentage of respondents who rated the extent to which CAs influence various services and/or decisions. Mean (M) influence was measured on a scale of 0 (not at all) to 4 (essential). 
According to respondents who currently use a CA, CAs' advice on crop disease and soil testing is considered, on average, very influential. Information on pesticide/herbicide applications and fertilizer rate, timing, and placement was rated overall as somewhat-to-very influential. Advice on the installation and maintenance of new/current conservation practices, however, was rated as just slightly-to-somewhat influential.

Several noteworthy factors help explain these results, including the relatively low degree of influence that CAs appear to have on conservation practices. First, the degree to which farmers trust CAs (both independent and retail) shows a weakly to moderately strong, positive association with how influential CAs' advice is perceived to be. Second, it is possible that our survey underestimated the degree of influence that CAs have on some or even all of the services we asked about. Without giving respondents an opportunity to answer "not applicable" - or some other similar answer to denote that their crop adviser does not typically offer recommendations on a given service - we suspect that some farmers simply defaulted to answering "not at all" when rating the degree of influence CAs have on any given decision/practice. Put another way, we have no way of differentiating in our results between respondents who answered "not at all" because they find CA's advice on a given practice to not be influential, and those who answered "not at all" simply because their CA has never offered conservation advice. This distinction, while subtle, is important. Interviews with farmers revealed that CAs typically do not offer conservation-related advice; farmers report being accustomed to hearing about new practices from other farmers as well as from sources more explicitly aligned with conservation (e.g. NRCS, SWCDs). However, interviewed farmers consistently expressed an openness to receiving field- and practice-specific conservation recommendations from their CA, and said they would find that information to be influential. Finally, in addition to the foregoing factors, perceptions of 
CAs' influence vary somewhat by farm size. In particular, CA's perceived influence on manure application, soil testing, and crop disease was moderately, positively associated with the size of a respondent's farm.

\subsection{Preferences and Attitudes toward CAs}

Overall, farmers expressed positive attitudes towards CAs, and an openness towards the idea of CAs delivering conservation information and recommendations. Respondents largely reported that they follow their CAs' recommended rates for phosphorous application, and that it is important that their CA is certified (Figure 5). A majority trust their CA with most of their farm management decisions, including recommendations on conservation practices (when they are offered). Considerably more farmers agreed than disagreed with statements "I trust my CA to make conservation recommendations," "I'd like my CA to provide farm and field-specific conservation advice," and "I think CAs will have needed information and answers about conservation practices." However, a large share of respondents - more than $50 \%$ - answered "neither agree nor disagree" to each of these items, as well as to questions that assessed preferences for having CAs help farmers apply to Farm Bill conservation programs, and those that queried farmers' willingness to pay CAs for this service. In follow-up interviews, farmers explained that this ambivalence comes from the relative infrequency with which CAs give currently give conservation advice; the idea of CAs providing this sort of service is new and therefore something about which farmers have not yet formed attitudes.

Regardless of their openness to receiving conservation recommendations from their CAs, farmers were generally unwilling to pay for this service. The vast majority (71\%) of respondents indicated they would not be willing to pay for these services, while $14.2 \%$ said they would be willing to pay $\$ 0.25 /$ acre. $5.5 \%$ and $5.9 \%$, respectively, were willing to pay $\$ 0.50 /$ acre and 


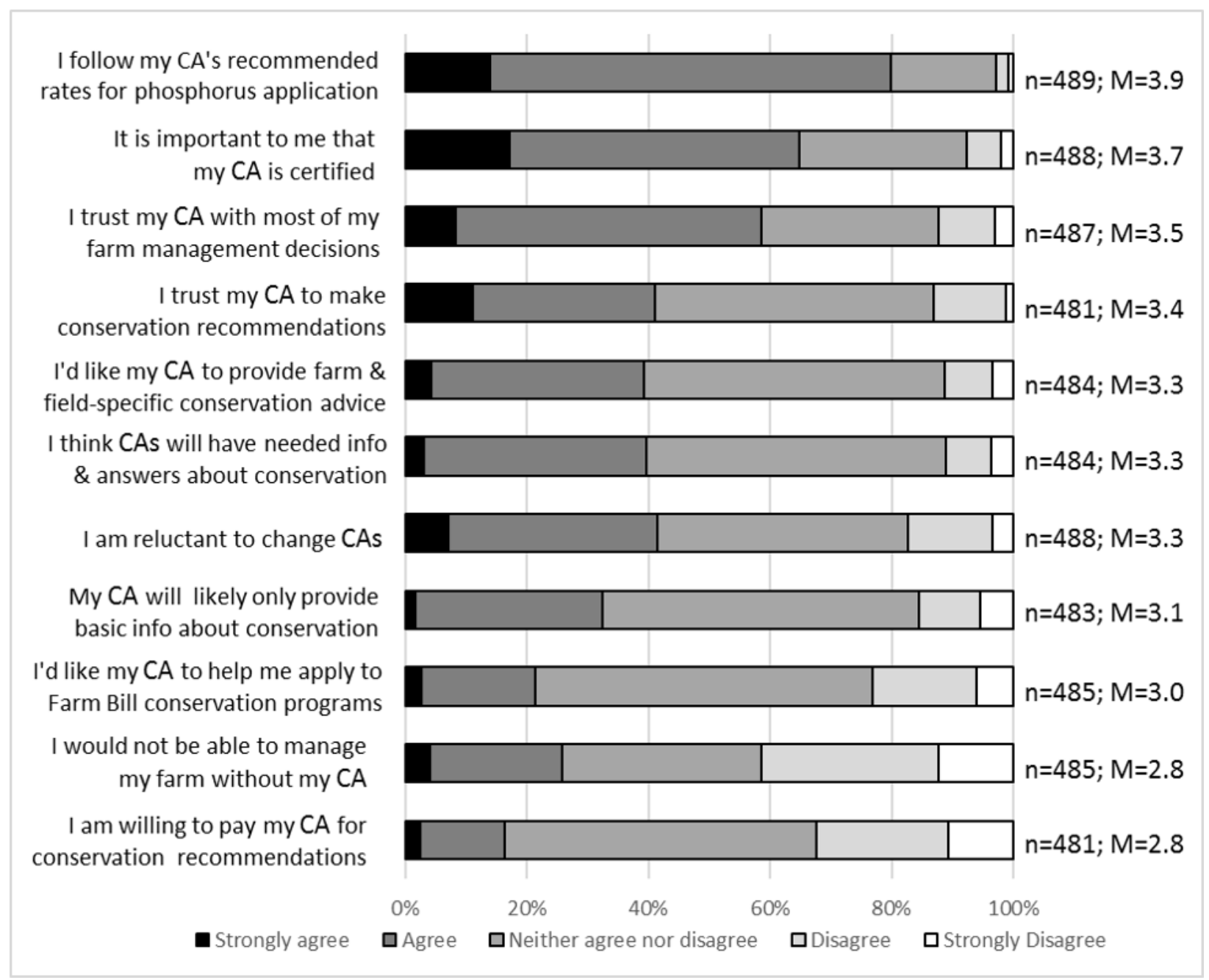

Fig. 5 Percent of farmers agreeing with statements about CAs, farm management, and conservation. Attitudes were measured on a scale of 1 (strongly disagree) to 5 (strongly agree).

$\$ 1.00 /$ acre, while the remaining 3.4\% said they would be willing to pay $\$ 2 /$ acre or more for help in applying to these programs. Some of this unwillingness to pay can likely be explained by loss aversion (c.f. Benartzi and Thaler, 1993) - that is, the tendency for farmers to prefer avoiding a known loss (i.e. paying CAs) than acquiring a potential gain (qualifying for federal cost-share money). Moreover, both interviewees and survey takers were largely unaware of the Saginaw 
Bay RCPP program, including its reliance on CAs to help farmers enroll in Farm Bill conservation programs. Additionally, farmers' willingness to pay CAs for farm- and fieldspecific conservation advice/recommendations unrelated to Farm Bill programs was not included in the survey and thus remains unknown. Interestingly, the amount that farmers were willing to pay was not statistically associated with their willingness to try cover crops, reduced tillage, NMPs, or develop a conservation plan, and only very weakly associated with their experience using other conservation practices (e.g. treatment wetlands, grade stabilization structures, and variable-rate applications of phosphorus and gypsum).

\subsection{CAs and Conservation Practices}

CAs appear to play a significant role in facilitating some conservation practices. For example, strong, positive associations were found between whether or not a farmer currently uses a CA, and farmers' level of experience with variable-rate phosphorus applications $\left(\chi^{2}[3]=154.9, p=.000\right)$, regular soil testing $\left(\chi^{2}[3]=160.4, p=.000\right)$, and gypsum applications $\left(\chi^{2}[3]=131.4, p=.000\right)$. Similarly, positive though less-strong relationships were observed between farmers' use of a CA and farmers' reported experience with drainage water management $\left(\chi^{2}[3]=59.2, \mathrm{p}=.000\right)$, grassed waterways $\left(\chi^{2}[3]=58.0, \mathrm{p}=.000\right)$, and grade stabilization structures $\left(\chi^{2}[3]=30.6, p=.000\right)$. In follow-up interviews, farmers talked about how CAs provided some of the initial guidance for practices like these, which tend to be newer and require more technical expertise to implement. Perhaps unsurprisingly, the largest effects were observed for practices that are associated with products and/or services that CAs typically sell e.g. NMPs, cover crop seeds, soil testing, variable-rate technology, and gypsum - compared to practices like grassed waterways or reduced tillage that do not readily have a saleable product or service associated with them. Likewise, moderate, positive associations were found between 
whether or not a farmer currently uses a CA and his/her willingness to try cover crops $\left(\chi^{2}[3]=103.4, p=.000\right)$, try reduced tillage $\left(\chi^{2}[3]=71.7, p=.000\right)$, use a nutrient management plan (NMP) $\left(\chi^{2}[3]=174.1, p=.000\right)$, and develop a conservation plan $\left(\chi^{2}[3]=11.7, p=.003\right)$ (Figure 6).

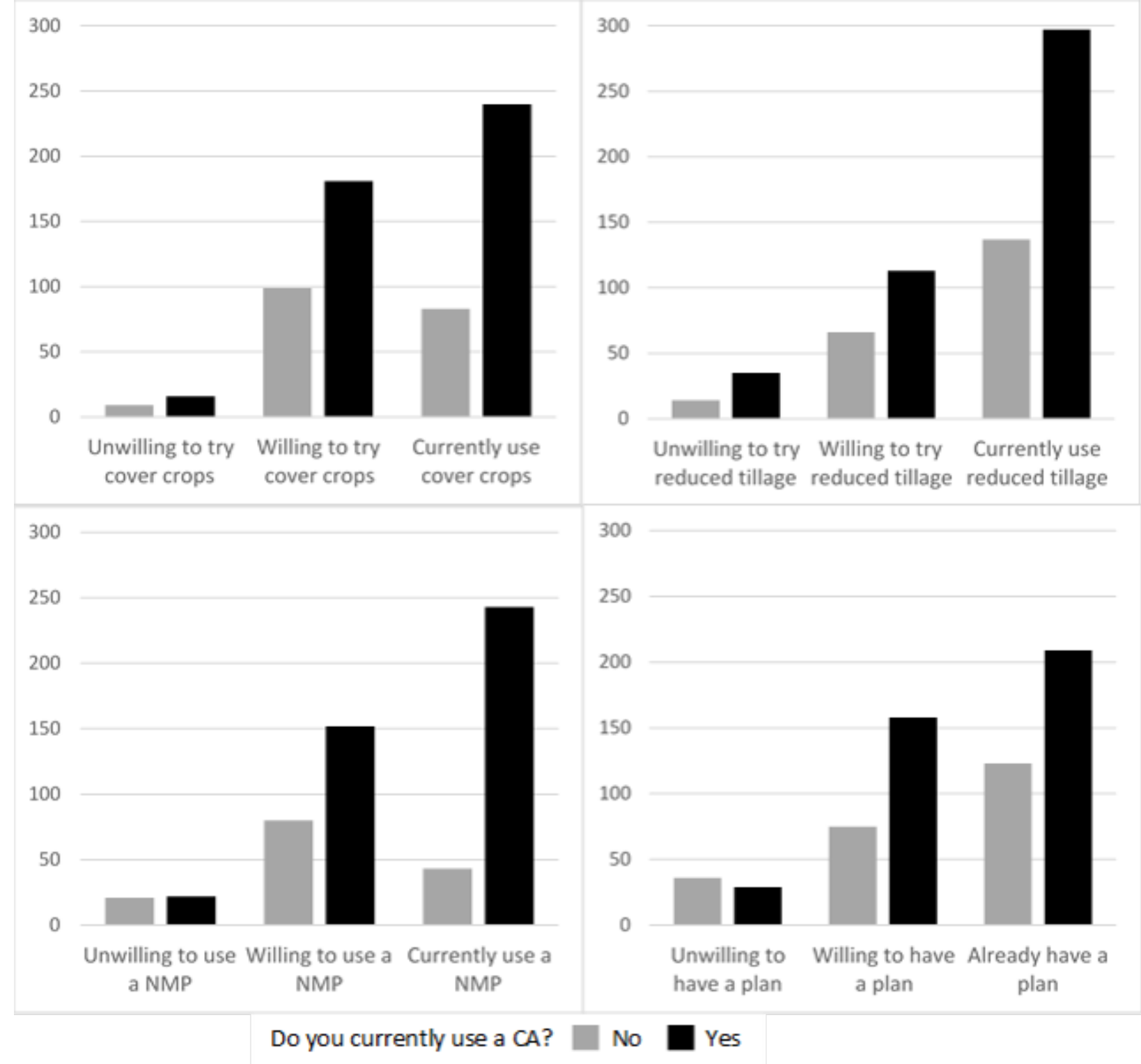

Fig. 6 Number of farmers who say they are willing to (a) try cover crops, (b) try reduced tillage, (c) use a nutrient management plan, and (d) develop a conservation plan, by whether or not a farmer currently uses a CA. 


\subsection{DISCUSSION}

Principle- Agent theory helps to explain the intra- and inter-institutional relationships that form in the pursuit of a goal or good, and how principals govern those contractual relationships through incentivizing and monitoring agent behavior. We argue that the pursuit of public goods such as water quality involves a complex principal-agent arrangement between society (via the government), farmers, and intermediaries associated with agricultural production and natural resources conservation (see Figure 1). However, the principal-agent dilemma of information asymmetry exists, wherein the government does not know whether incentives are sufficient to motivate appropriate farmer conservation behavior, nor can the government adequately verify that conservation practices are actually carried out at the field scale. In order to overcome these dilemmas, the government contracts out to third-party intermediaries to perform the role of incentivizing and verifying farmer behavior. Intermediaries accomplish this through monitoring and sanctioning farmer behavior (Mitnick 1980; McCubbins and Schwartz 1984). We argue that CAs could potentially be effective intermediaries who, as conservation entrepreneurs, complement the function and expand the impact of existing intermediaries (e.g. NRCS, SWCDs) by reducing information asymmetry between government and farmers, and ultimately increasing farmers' adoption of conservation practices. Understanding farmer's perceptions of CAs assuming this entrepreneurial role, however, is a necessary precursor to assessing how that role may be structured in the agricultural sector's already-complex informational and financial milieu.

Despite the theoretical advantages of partnering with CAs to deliver conservation information and recommendations (i.e., high levels of trust and influence on farm decisions, and frequent contact with farmers), the concept of including CAs as conservation entrepreneurs is 
relatively new to farmers, and thus somewhat ambiguous in their views. This lack of well-formed perceptions and preferences for CAs providing conservation advice was reflected in the survey results, while interview results highlighted farmers' ambiguity about the form and function of this hypothetical relationship. Interviews reveal that farmers are largely open to receiving conservation advice from CAs - particularly field- and farm-specific advice - but are uncertain as to whether (1) CAs would be interested in performing this role, (2) their willingness to pay for this information themselves, and (3) who would step in to subsidize this information service, if indeed farmers do not pay for it themselves.

While there is uncertainty and ambiguity of how the role of CAs as conservation entrepreneurs will be structured, our results suggest several ways that CAs can reduce information asymmetry in - and thereby enhance the impact and effectiveness of - the existing principal-agent model as it applies to soil and water conservation. For example, CAs could act as an initial clearinghouse and point of contact between farmers and conservation program intermediaries (e.g. NRCS, environmental NGOs). By matching information from farmers with knowledge of governmental and non-governmental conservation programs, CAs could align the management goals of farmers (e.g. increasing soil organic matter) with conservation practices (e.g. cover crops) that fulfill the conservation goals and funding opportunities of existing programs. In addition, CAs could streamline the application process associated with federally funded conservation programs. While farmers typically are required to submit lengthy paperwork about their farms' operational characteristics and management practices before finding out whether they will qualify for some conservation programs (particularly those associated with the Farm Bill), CAs could use their knowledge of farms' operations to effectively screen them for suitability and potential eligibility for these programs before farmers attempt to enroll. If the 
barriers to entry into federal programs are perceived by a farmer to be too high, the CA could direct that farmer to similar, less restrictive programs sponsored by non-governmental entities. Such knowledge and frequent on-farm presence, moreover, would allow CAs to monitor farmer behavior - a necessary function to preserve the integrity and sanctioning capability of the principal-agent relationship (McCubbins and Schwartz 1984). Finally, their access to extensive client networks, along with their knowledge of individual farmers' conservation attitudes and operational motivations, puts CAs in the position to strategically extend the reach of existing conservation efforts. In sum, CAs can leverage their knowledge of both individual farm characteristics as well as the broader conservation program landscape to advance the respective goals of all parties involved in the principal-agent relationship.

While the principle-agent dilemma could be partially solved with CAs acting as conservation entrepreneurs, including them as intermediaries introduces another dilemma. At present, although the farmers who participated in our study are open to receiving conservation information and advice from CAs, they are considerably less willing to pay for these additional services. If CAs are not provided direct compensation from their clients, how would CAs directly or indirectly benefit, and/or be motivated to help society and the government achieve conservation goals? If an incentive plan were created to overcome this challenge - that is, if CAs effectively became agents of government/society for the purpose of increasing farmer enrollment in conservation programs - how would the ensuing dilemma of information asymmetry (vis-à-vis CAs) be addressed in this principal-agent setup? Who would monitor CA behavior (i.e. ensure that they are indeed providing conservation information) and link it to farmer behavior (implementation of conservation practices)? Future research should address these questions and include an assessment of the value added by CAs in motivating the adoption of conservation 
practices. Future research should also look into stewardship theory of principle-agent dilemmas to understand why certain CAs would be more likely to provide conservation advice than others.

\subsection{CONCLUSION}

The goal of this study was to evaluate farmers' trust in CAs as current or potential sources of conservation information, assess the degree to which CAs influence farmers' conservation practices, and understand farmers' attitudes with respect to CAs as potential conservation partners. Grounding our study in the principal-agent theory, we argue that CAs are uniquely positioned between government (principle) and farmers (agent) - especially compared to current intermediaries (NRCS, SWCDs) - and may thus be effective intermediaries as conservation entrepreneurs in reducing information asymmetry and increasing adoption of conservation practices.

Although much is written about farmers' trust in CAs for general agronomic advice, less is known about whether or not this trust can translate into CAs acting as conduits of information on agricultural conservation practices. We used survey and interview data from farmers in the central Great Lakes region to further our understanding of the barriers and opportunities associated with CAs assuming the role of conservation entrepreneurs. Our findings indicate that farmers moderately trust CAs for conservation information. We also found that farmers rated CAs as slightly-to-somewhat influential with respect to seeking advice on installation and maintenance of conservation practices. Farmers also expressed positive attitude towards CAs, and in interviews were very open to the idea of CAs delivering conservation information and recommendations. Overall, our findings indicate that although farmers are open to receiving conservation advice from CAs, they are uncertain about CAs' interest in taking on this role, and 
how the associated services will be compensated and /or incentivized. While the principle-agent dilemma is partially solved by including CAs as intermediaries, the dilemma now extends to CAs. Farmers are open to receiving information and advice from CAs, but are less willing to pay for the additional services. If CAs are not being provided incentives via their relationship with their clients, how will CAs be motivated to help society and the government achieve conservation goals? If an incentive plan is created, how will the dilemma of information asymmetry may be addressed by using CAs as conservation entrepreneurs, if there is no monitoring CA behavior (i.e. providing conservation information) and linking it to farmer behavior (i.e. implementation of conservation)? Future research should address these questions and include an assessment of the value added by CAs in motivating the adoption of conservation practices. Future research should also look into stewardship theory of principle-agent dilemmas to understand why certain CAs would be more likely to provide conservation advice than others. 


\section{REFERENCES}

Allan, J.D., McIntyre, P.B., Smith, S.D.P., Halpern, B.S., Boyer, G.L., Buchsbaum, A., Burton Jr., G.A., Campbell, L.M., Chadderton, W.L., Ciborowski, J.J.H., Doran, P.J., Eder, T., Infante, D.M., Johnson, L.B., Joseph, C.A., Marino, A.L., Prusevich, A., Read, J., Rose, J.B., Rutherford, E.S., Sowa, S.P., \& Steinman, A.D. (2013). Joint analysis of stressors and ecosystems services to enhance restoration effectiveness. Proceedings of the National Academy of Sciences, $110(1): 372-377$

Benartzi, S., \& Thaler, R. H. (1993). Myopic loss aversion and the equity premium puzzle (No. w4369). National Bureau of Economic Research.

Braun, D., \& Guston, D. H. (2003). Principal-agent theory and research policy: an introduction. Science and public policy, 30(5), 302-308.

Carr, A., \& Wilkinson, R. (2005). Beyond participation: Boundary organizations as a new space for farmers and scientists to interact. Society and Natural Resources, 18(3), 255-265.

Chantre, E., \& Cardona, A. (2014). Trajectories of French field crop farmers moving toward sustainable farming practices: change, learning, and links with the advisery services. Agroecology and Sustainable Food Systems, 38(5), 573-602.

Cerf, M., Guillot, M. N., \& Olry, P. (2011). Acting as a change agent in supporting sustainable agriculture: how to cope with new professional situations?. Journal of Agricultural Education and Extension, 17(1), 7-19.

Coleman, J. S. (1990). Foundations of Social Theory (BelknapPress, Cambridge). 
Cousins, K. (2006). Principals, Agents, and Public Goods: Information and Structural Complexity in Policy Implementation Systems. In 47th Annual International Studies Association meeting, March (pp. 22-25).

Davenport, M. A., Leahy, J. E., Anderson, D. H., \& Jakes, P. J. (2007). Building trust in natural resource management within local communities: a case study of the Midewin National Tallgrass Prairie. Environmental management, 39(3), 353-368.

Davidson, E., Galloway, J., Miller, N., \& Leach, A. (2014). N-related greenhouse gases in North America: innovations for a sustainable future. Science Direct, 9-10, 1-8.

Dillman, D., Smyth, J., \& Christian, L. (2008). Internet, Mail, and Mixed-Mode Surveys: The Tailored Design Method. John Wiley \& Sons.

Eller, D. (2016, November 18). Report: Iowa, states failing to cut nutrient pollution without EPA push. The Des Moines Register. Retrieved December 6, 2016, from http://www.desmoinesregister.com/story/money/agriculture/2016/11/17/epa-must-push-iowamississippi-river-states-cut-nutrient-pollution-report-says/93954770/

Eller, D. (2015, October 27). Iowa counties: Water Works lawsuit is all wet. The Des Moines Register. Retrieved December 6, 2016, from http://www.desmoinesregister.com/story/money/2015/10/27/iowa-counties-water-works-lawsuitall-wet/74618820/

Fales, M.K., Dell, R., Herbert, M.E., Sowa, S.P., Asher, J., O’Neil, G., \& Doran, P.J. (2016). Making the leap from science to implementation: Strategic agricultural conservation in Michigan's Saginaw Bay watershed. Journal of Great Lakes Research, 42(6):1372-1385. 
Floress, K., Prokopy, L. S., \& Ayres, J. (2011). Who's in charge: Role clarity in a Midwestern watershed group. Environmental management, 48(4), 825-834.

Gal, P, Dugue, P., Faure, G., \& Novak, S. (2011). How does research address the design of innovative agricultural production systems at the farm level? A review. Agricultural Systems, 104(9), 714-728.

Hamilton, H., \& Reaves, E. (2014). Transforming food \& Ag policy: Food and beverage company sustainable sourcing initiatives in farming regions. Agree Food and Policy.com.

Harden, N. M., Ashwood, L. L., Bland, W. L., \& Bell, M. M. (2013). For the public good: weaving a multifunctional landscape in the Corn Belt. Agriculture and human values, 30(4), 525537.

Ingram, J. (2008). Are farmers in England equipped to meet the knowledge challenge of sustainable soil management? An analysis of farmer and adviser views. Journal of Environmental Management, 2, 214-228.

Kerr, J., DePinto, J.A., McGrath, D., Sowa, S.P., \& Swinton S.M. (2016a). Sustainable management of Great Lake watersheds dominated by agriculture land use. Journal of Great Lakes Research, 42(6), 1252-1259.

Kerr, J.M., Meersman, M., Fuller, E., \& Fales, M.K. (2016b). Exploring the potential role of public drain managers in motivating agricultural conservation practices. Journal of Great Lakes Research, 42(6), 1386-1394.

Knowler, D., \& Bradshaw, B. (2007). Farmers' adoption of conservation agriculture: A review and synthesis of recent research. Food policy, 32(1), 25-48. 
Kromm, D., \& White, S. (1991). Reliance on source of information for water-saving practices by irrigators in the High Plains of the U. S. A. Journal of Rural Studies, 7(4), 411-421.

Latacz-Lohmann, U., \& Van der Hamsvoort, C. (1997). Auctioning conservation contracts: a theoretical analysis and an application. American Journal of Agricultural Economics, 79(2), 407418.

Lemos, M. C., Kirchhoff, C. J., \& Ramprasad, V. (2012). Narrowing the climate information usability gap. Nature Climate Change, 2(11), 789-794.

Lemos, M.C., Lo, Y., Kirchhoff, \& Haigh, T. (2014). Crop advisers as climate information brokers: building the capacity of US farmers to adapt to climate change. Climate Risk Management, 4-5, 32-42.

Mase, A., Babin, N., Prokopy, L., \& Genskow, K. (2015). Trust in sources of soil and water quality information: implications for environmental outreach and education. Journal of the American Water Resources Association, 51(6), 1656-1666.

Meynard, J., Cerf, M., Guichard, L., Jeuffroy, M., \& Makowski, D. (2002). Which decision support tools for the environmental management of nitrogen? Agronomie, 22(7-8), 817-829.

McCubbins, M. D., \& Schwartz, T. (1984). Congressional oversight overlooked: Police patrols versus fire alarms. American Journal of Political Science, 165-179.

Michigan Department of Agriculture and Rural Development (2016). Facts about Michigan Agriculture, http://www.michigan.gov/mdard/0,4610,7-125-1572-7775--,00.html MDARD.

Mitnick, B. M. (1980). The political economy of regulation: Creating, designing, and removing regulatory forms. New York: Columbia University Press. 
Norvell, J., \& Lattz, D. (1999). Value-added crop, GPS technology and consultant survey: summary of a 1998 survey of Illinois farmers. Working paper, College of Agricultural, Consumer and Environmental Sciences, University of Illinois.

Osmond, D., Hoag, D., Luloff, A., Meals, D., \& Neas, K. (2015). Farmers' use of nutrient management: lessons from watershed case studies. Journal of Environmental Quality, 44, 382390.

Paine, M., Nettle, R., \& Coats, S. (2004). Learning and professional development in advisery services: supporting the reflective practitioner. (Pre)Proceedings of the $6^{\text {th }}$ European IFSA Symposium.

Potoski, M., \& Prakash, A. (2002). Protecting the environment: voluntary regulations in environmental governance. Policy Currents, 11(4), 9-14.

Prokopy, L., Haigh, T., Mase, A., Angel, J., Hart, C., Knutson, D., Lemos, M., Lo, Y., McGuire, J., Morton, L., Perron, J., Todey, D., \& Widhalm, M. (2013). Agricultural advisers: a receptive audience for weather and climate information. Weather, Climate, and Society, 5, 162-167.

Prokopy, L., Towery, \& Babin, N. (2014). Adoption of agricultural conservation practices: insights from research and practice. Purdue Extension, FNR-488-W.

Rissman, A. R., \& Carpenter, S. R. (2015). Progress on Nonpoint Pollution: Barriers \& Opportunities. Daedalus, 144(3), 35-47.

Romig, D. E., Garlynd, M. J., \& Harris, R. F. (1996). Farmer-based assessment of soil quality: a soil health scorecard. Methods for assessing soil quality, (methodsforasses), 39-60. 
Rosenberg, S., \& Margerum, R. D. (2008). Landowner motivations for watershed restoration: lessons from five watersheds. Journal of Environmental Planning and Management, 51(4), 477496.

Saginaw Bay Watershed Initiative Network (2016). Info On Watershed. Retrieved on September 1, 2016 from http://www.saginawbaywin.org/info_on_watershed/

Shah, D., Esker, P., Bradley, C., Conley, S., Paul, P., \& Robertson, A. (2015). A profile of and communication between certified crop advisers and maize growers in the Midwest United States. Social Science Research Network, December, 2015.

Sheriff, G. (2005). Efficient Waste? Why farmers over-apply nutrients and the implications for policy design. Agricultural \& Applied Economics Association, 27(4), 542-557.

Sowa, S.P., Herbert, M.E., Mysorekar, S.S., Annis, G., Hall, K., Nejadhashemi, A.P., Woxnicki, S.A., Wang, L., \& Doran, P.J. (2016). How much conservation is enough?: Defining implementation goals for health fish communities. Journal of Great Lakes Research, 42(6), $1302-1321$.

Stoneham, G., Chaudhri, V., Ha, A., \& Strappazzon, L. (2003). Auctions for conservation contracts: an empirical examination of Victoria's BushTender trial. Australian Journal of Agricultural and Resource Economics, 47(4), 477-500.

Stuart, D., Schewe, R., \& McDermott, M. (2014). Reducing nitrogen fertilizer application as a climate-change mitigation strategy: Understanding farmer decision-making and potential barriers to change in the US. Land Use Policy, 36, 210-218. 
US Department of Agriculture - Natural Resources Conservation Service, (2016). Regional Conservation Partnership Program. Retrieved January 10, 2017, from https://www.nrcs.usda.gov/wps/portal/nrcs/main/national/programs/farmbill/rcpp/\# US Environmental Protection Agency, (2016). Water Quality Assessment Report. Retrieved September 1, 2016, from https://ofmpub.epa.gov/waters10/attains watershed.control\#causes US Environmental Protection Agency, (2012). Overviews and Factsheets. Retrieved September 1, 2016, from https://www.epa.gov/greatlakes

Wolf, S. (1995). Cropping systems and conservation policy: the roles of agrichemical dealers and independent crop consultants. Journal of Soil and Water Conservation, 50(3), 263-270. 